\title{
The connotations of 'Value' in heritage crafts, and their relevance to a skill-based education towards knowledge economic systems
}

\author{
Heitor Alvelos ${ }^{*}$, Abhishek Chatterjee ${ }^{b}$ \\ alD+/Unexpected Media Lab, University of Porto \\ bID+/Unexpected Media Lab, London School of Design and Marketing \\ *halvelos@fba.up.pt
}

\begin{abstract}
:
The present article addresses various connotations of "Value" as present in contemporary material culture and heritage crafts. The authors posit that "Value" is undergoing a process of re-signification that is semantically reductive, brought to tacitly invoke strict monetary gain; we argue that this bears adverse effects in terms of perception and action towards other consequential values related to craft. The article discusses further value significations of crafts, and addresses how embedded specialised skills can become key to configuring knowledge-based economic systems based in creative human enterprise. Correspondingly, the research argues for practice-based learning of craft techniques in Design schools as an interface towards a pedagogy of valuation based on unmediated experience - and consequent replicable pathways for sustaining the validity and applicability of heritage industries.
\end{abstract}

Keywords: Heritage Crafts; Knowledge Transfer; Design Research; Design Semantics

\section{Prelude: a blessing in disguise?}

In late March 2021, a controversy surfaced in Portuguese media channels involving U.S. Clothing Designer Tory Burch: her Spring 2021 collection included a jumper featuring motifs and weaving techniques claiming to be of Mexican inspiration; in truth, the item's design and imagery were largely lifted from traditional wear originating in Póvoa do Varzim, Portugal, as far back as the late 19th Century. Further to the mis-attribution, Burch sold her version online for nearly nine times the price local Póvoa shops charged for the hand-crafted original.

As the controversy amplified on social media, Burch was threatened with legal action by the Portuguese Ministry of Culture; after due correction and corresponding public apology, Burch's jumper ended up being withdrawn from sale.

The Burch episode turned out to be somewhat of a blessing in disguise for the original Póvoa garment: as a consequence of media controversy and ensuing public attention, traditional jumpers 
saw an exponential increase in demand, and a renewed interest in the craft itself: as of late April, 2021, the attendance of weaving courses organised by the Municipality of Póvoa had sold out.

This episode illustrates how the subject of value reaches beyond monetary gain, often the protagonist of paradoxical mechanisms that amplify a defiance of authenticity and attribution. These mechanisms provide somewhat perverse opportunities for a just recognition, valuation and advancement of crafts and outputs within their original provenance: a kind of antidote to the volatile sampling experience of online shopping.

The longer-term implications of the Burch-Póvoa incident remain to be comprehended, but the episode itself has provided a timely reminder of the complexity that lies at the center of the concepts of "Value" and "Originality" - as well as illustrating how valuation has now largely been superseded by speculation, even as it pertains to material culture.

The present article elaborates on the above challenges from the perspective of an ongoing research project, Unexpected Media, where similarly perplexing dynamics are often witnessed and implemented; the above recount signals further developments to be incorporated.

\section{Introduction}

The present article argues that terms such as "Value", "Viability" and "Wealth" in present times are undergoing a process of semantic re-signification that may be ominously reductive, lying in open contrast to their otherwise polysemic nature, with particular impact in creative processes.

A scrutiny of the polysemic nature of the word "Value" first reveals a corresponding multi-modality: as the term shifts, so a set of actions are consequently expected and performed. At the root of this interest in the term "Value" and associated actions is the hypothesis that its current dominant definitions have become semantically reductive, brought to tacitly invoke strict monetary gain; we argue that this bears adverse effects in terms of perception towards other consequential values related to craft practices, and strive to mediate a polysemic resurgence of the term, accompanied by a corresponding pedagogy of valuation.

Within the research project, the scrutiny of the term "Value" has been preceded by an exploration and calibration of the term "Media", with parallel conclusions and implications: "Media" has lately come to signal the range of available digital technology, when in fact both its etymological roots and historical employment have pointed towards various processual geometries, rather than a strict set of tools. This semantic re-investment in the term "Media" brings its own set of philosophical issues; however, in the context of Unexpected Media, it intends to translate into action.

This action is twofold: on one hand, the unpacking of the term "Media" provides an increased awareness of the impact of technological development beyond the experience of the digital; on the other hand, it invites us to reconsider dictated technological obsolescence as itself a construction, and consequently re-evaluate/re-ignite so-called "dead media". 


\section{The conundrums of value, wealth and viability}

A key goal of Unexpected Media is the translation of the above conundrums into practice, particularly in regards to traditional creative activities that have been eroded as a consequence of technological and economic - and semantic - acceleration. We argue that reclaiming an expanded lexicon is the first step towards acknowledging intrinsic and subjective components of both the creative product and the creative experience.

When denoted in the context of traditional making, the term "Wealth" can regress from invocations to historical legacies, empirical and tacit wisdom, practical know-how, interpersonal connections, and existential resolutions - in some cases dating back centuries - towards developing a more simplistic allusion to business liquidity.

For vulnerable traditional practice cultures and communities, the insularity of such assessment and its normalisation can place added pressure on stakeholders, resulting in a myriad of complications: from the loss of authenticity in traditional products and workflows to abandonment of practice which, if occurring within regionally localised communities, can lead to rapid depopulation of nonurban practice bases. We thus posited that in order not to jeopardise the continuity of systems of traditional knowledge comprising techniques and workflows honed over centuries of practice, it has become imperative for purveyors of culture and education to identify, study, mediate and disseminate subjective worth and intangible virtues of traditional making.

\section{Contextual and conceptual frameworks}

The notion of value is a core factor in debating convention versus contemporaneity, entailing numerous rationales and interpretations, including tangible/intangible, real/perceived and direct/relative. Jokilehto (1999) sees the value factor as crucial to both state-of-the-art creative production and conservation efforts that focus on heritage infrastructure. Traditional making has historically found applicability in either context, wherein craft-based approaches have utilised diverse interpretations of media, tools, and knowhow in scenarios across the creative spectrum. In recent years, craft approaches have been integrated into cutting-edge practices such as independent game development (Westecott, 2012) and additive manufacturing (London based Betatype, for example); and at the same time, more typical interpretations such as the handloom sector continue providing means of sustenance for marginalised communities worldwide. Unexpected Media thus activated "Anti-Amnesia: design research as an agent for narrative and material regeneration and reinvention of vanishing Portuguese manufacturing cultures and techniques". This is a spin-off research front mainly arguing that the process to determine the validity of a craft practice should incorporate a deeper contextual awareness and consideration of medium and long-term ramifications, and not just short-term profitability.

The contribution of the crafts sector has become a focal point of creative and analytical studies in recent decades. As global economies move towards knowledge-based paradigms that place onus on specialised know-how for creating value, the scrutiny of the crafts sector should ideally gain further momentum. Shwarz and Yair (2010) touch upon aspects related to the overall worth of craft makers and industries, wherein "the value of 'craft' in contemporary economy and society is not limited to the value produced by those identifying themselves as makers, or solely held within the objects they produce". The value proposition of crafts, therefore, is multilayered, and goes beyond the attributable physical and/or material worth of the produced objects, as also discussed by Sennett (2008). 
However, as Anti-Amnesia has observed, such conversations are happening at a time when the ground reality of traditional small-scale industries and practices in Central and Northern Portugal is indicating a contrary and disconcerting future: The emergence and rapid proliferation of modern commercial, technological, and consumption-related precepts has not afforded many traditional practice communities from these regions a sufficient amount of time or representation regarding transition from past praxis.

Traditional makers are consequently facing unprecedented levels of competition and market loss from cheaper, mass-produced alternatives. An untenable disparity exists between craft and cottagescale industries and larger, more resourceful entities having a global footprint, in terms of workflows, organisation structures, business aims and approaches, outreach, and resource availability.

Therefore, the formal attribution of traditional practices as commercial-first activities invariably leads to their valuation on economic-only parameters, whereby, (a) the focus goes to tangible value aspects while actively downgrading intangible aspects; (b) additional pressure is put on the practice communities to reinvent themselves towards inculcating a bottom-line mindset, and consequently compromising on deeper meaning and rootedness; and (c) the short-term view of such exercises debases spills over economic effects of craft and traditional making that can occur within medium to long term spans, and have industry-wide implications. Also, as illustrated by the Burch-Póvoa online conflict, the relative obscurity of certain localised practices in social media and the internet puts them at risk of cultural appropriation - while ensuring a kind of hyper-scrutiny that manages to readily denounce cultural appropriation to the extent of caricature.

Thus, the prevailing circumstances indicate a vital need for mediations to comprehend a broader spectrum of issues behind the accruing uncertainty. For instance, in the case of a key case study partner - a unique millenary weaving culture from Central Portugal - emphasis has been laid on internally showcasing the contemporary relevance of the traditional craft as a direct response to viability related apprehensions arising within the practice community, which has been leading to abandonment in recent times. The approach has involved deconstructing the overall value proposition of the craft into individual value outcomes, such as pertaining to aesthetics, tactility, and importance to regional culture and history, among others. The corresponding challenge has been to further examine multimodal implications of Media towards identifying conduits that can best serve to highlight potential advantages; and a number of exploratory undertakings articulating natural complementarities between craft, design and media have produced results of interest for both the practice community and the researches involved. The continuity of practice, another key concern of the centre's intervention with the weaving community, is being secured through intersectoral collaborations, such as with other, better-situated industries such as footwear, and by establishing long-term mutually advantageous relationships with academia, and in particular, art and design education. We see such conjunctions as imperative for the craft community to re-instill the joy of making (Sennett, 2008), and for its underlying structure to evolve beyond the current state of flux.

In concurrence, Anti-Amnesia has also paid keen attention to restorative measures regarding the preservation of heritage craft techniques emanating from the creative community at large. In this respect, it has collaborated with and learned from creatives and cultural activists who have been involved in promoting community-based engagement with local heritage practices and communicating their significance to a global audience.

An example in this regard is an initiative that aims to sustain Portuguese Azulejos tile making by leveraging typical points of conflict, such as tourism boom, to work in favor of the restitution of traditional forms and aesthetics. Anti-Amnesia has studied and participated in the initiative's public 
workshops, contributed to its crowdsourced campaigns for developing a comprehensive visual library of original patterns, and even aided in tile rescue missions for recovering discarded century-old hand painted specimens from building renovation sites: with the fundamental objective of apprehending

Contexts such as the above have been selected as case studies on the basis of their varying degrees of technological and/or cultural obsolescence, and entailing sets of custom challenges. Practices such as hand-painted tile-making are long outmoded, but due to cyclically rekindling interest in manuality, they find renewed relevance within niche markets and interest groups. On the other hand, the millenary hand weaving practice's situation is descriptive of consternations being currently faced by unique localised craft industries that are on the brink of disappearance and require mediation with greater immediacy. Studies on similar cases, such as that of tin toy-making (Dolbeth \& Rocha, 2020) have shown how abruptly such situations can precipitate unless the early indications are paid sufficient heed to and resolved through collaborative interfacing between citizens, civic entities and administrative bodies.

\section{Methods of enquiry}

In critiquing contemporary interventions for sustenance of dissipating craft practices, Thomas et. al. (2011) state the importance of understanding and addressing the "deep-rooted issues that marginalize such groups in the first place." In deliberating resolutions, it is therefore imperative to incorporate emic perspectives. Accordingly, Anti-Amnesia's research methodology was underpinned by ethnographic methods from the social sciences (Pink, 2007; Rose, 2011) that have proven to be effective in securing suitable conditions for building trust, reciprocity, and shared vision, when applied in an articulated manner with more formative approaches of design (de Almeida, 2012).

Furthermore, the authors argue for a presence of Design as mediator of both enquiry and practice, a facilitator of what is essentially and primarily the work of an other: in the present case, the craftsman. The direct correlation between what Unexpected Media argues regarding a reconfiguration of the term "Media" and the proposed practice of "Mediation" should be selfevident.

The research team therefore worked closely with active and associated members of the practice communities in order to integrate their experience in fact-finding and solution-making, as well as for uncovering facets that could be leveraged in creating all-round value. The ethnography-based mediation actions of the project thus included: audiovisual documentation of testimonies, specimen collection, and reciprocal capacitation in both the making and the imagining of further valuation of the crafts at stake.

Anti-Amnesia has placed particular emphasis on possibilities through education, and perceived design pedagogy as crucial to sustaining traditional creative processes and approaches: Design students as future makers and creatives become an important component for the project to further develop the timeless and multifaceted value of crafts. A core integration of student involvement in $\mathrm{BA}$ and MA curricular activities was thus established, across the following lines of intervention:

- Learning: hands-on production of artefacts, supervised by the original craftspeople themselves.

- Ethnography: collecting, archiving and interpreting source materials.

- Reinterpretation: furthering traditional elements through unexpected processes of recontextualization. 
- Design: developing sustainable product and communication strategies and prototypes.

- Dissemination: both internally, through curricular maintenance, and externally, ensuring mechanisms of valuation and proper historical/contemporary attribution.

Curricular integration was established through field trips, practice workshops and project-based dissertations; the empirical evidence indicated a keenness by students towards discovering and engaging with traditional making contexts and processes - upon being provided with opportunities and stimuli. This evidence further corroborates the polysemic vocation of the term "Value", translated into what we call a pedagogy of valuation - whereby students develop a personal interest and investment in the practices at stake, by experiencing and ultimately embodying the respective processes themselves. We argue that, by acknowledging and unpacking "Value" as a core polysemic term within Design curricula, we will be decisively contributing to a critical ability to confer and recognise meaning among contemporary instances of sensorial over-abundance and random cultural circulation.

\section{Conclusions}

The above educational endeavours have confirmed that provisions for a long-term dialogue with education may be key for fading craft and traditional industrial practices to hold continued and farreaching value in economy, society, and culture. This may help traditional industries and activities avoid being restrictively classified as local cultural showpieces, and aiding in curtailing situations of cultural mis-appropriation by external entities - often resulting in an intrinsic devaluation of intangible value that is potentially laid upon the corresponding products.

Ligations in this regard can be mutually meaningful, since:

- A wider academic legitimisation of crafts and related contexts towards developing activities or research fundamentally considers direct and relative gains.

- Academic evaluation/research also serves as reference material for policy makers; researchers and educators may detail methodological aspects that can promote qualitative values in conjunction with the quantitative values that policy makers expect (Thomas, et. al., 2011).

- Collaboration with design education can create grounds for a sustained culture of innovation in crafts, specifically in terms of evolving product and communication strategies, based on activating synergies between ideation and workmanship (Pye, 1968).

- Traditional craft cultures can benefit from technological advancements that may help disseminate their practice to broader markets and audiences - "The practical value of new technology can lie in both the positive attribute of original experimentation, through the creative exploration of new potentials with original results and production/design efficiencies" (Woolley, 2010).

- Students, in turn, can find conditions for further impact of their skills and knowledge towards critical situations.

The above actions in educational contexts ensure a culture of valuation that stands in stark contrast with speculative transaction; as such, it may be argued that a further layer of the term emerges: "Value" as an ethical pursuit, whereby all involved in creative acts, the renewal of traditions and the viability of legacies are dignified in the process. The bringing together of multidisciplinary creative 
communities representing craft and design within a learning-based dialogue also helps "externalise" (Polanyi, 1966) informal know-how towards co-exploring further prospects of continuity.

\section{Coda: unexpected developments}

Field work within the scope of Anti-Amnesia research was largely conducted before the COVID-19 pandemic dramatically shifted economic sectors on a global scale, with an inevitable impact on the aforementioned case studies. The project thus faced the dilemma of either accepting a measure of existential self-doubt, or reporting on tangible outcomes within pre-pandemic premises. The project chose the latter, as envisioning scenarios could only be speculative in face of the current volatility and uncertainty: at a stage when the project was nearing completion, such a level of speculation would actually risk future self-invalidation.

Therefore, while acknowledging current major shifts in economic and technological factors in the project partners' ecosystems, Anti-Amnesia opted to remain faithful to the originally defined premises of the research - while maintaining an attentive eye on both rapid developments, and the suitability of prior research once a measure of stability is reconquered. For now, however, even emerging perplexities such as the aforementioned Burch-Póvoa conflict reassure us there are indeed ways forward, regardless of how disconcerting they might seem at the moment - and as as the variables seem to be developing faster than our ability to apprehend and stabilise them, those ways will deserve a key role in future formulations.

We conclude by positing that the pandemic has placed further emphasis on the financial connotations of the term "Value" as a currency of survival; however, if anything, the Burch-Póvoa episode stands as a stark reminder that, before translating as a number, "Value" also happens to be a verb - and as such, is a call for action.

\section{References}

Albino, C. (2017). À procura de práticas sábias: design e artesanato na significação dos territórios [Looking for wise practices: design and handicraft in the significance of the territories]. Coimbra: Centro de Formação Profissional do Artesanato.

Alvelos, H. (Ed.) (2019). Unexpected Media Lab. Porto: ID+/University of Porto.

Alvelos, H., \& Chatterjee, A. (2021). Anti-Amnesia: : design research as an agent for narrative and material regeneration and reinvention of vanishing Portuguese manufacturing cultures and techniques. (Project website). Retrieved 19 May, 2021, from http://antiamnesia.fba.up.pt

Alvelos, H., Chatterjee, A., \& De Almeida, P. C. (2021). Anti-Amnesia: design research as an agent for narrative and material regeneration and reinvention of vanishing Portuguese manufacturing cultures and techniques. Porto: ID+/Unexpected Media Lab.

de Almeida, P. C. (2012). Brand Archives: the rescuing of locally specific brand identities as a graphic design response to the globalization of visual identity. PhD thesis, Vol. 1. London: Central Saint Martins, University of the Arts London.

Chatterjee, A., \& De Almeida, P. C. (2016). Sapatilhas: cultural signification and industrial legacy. Conference poster. Lisbon: Encontro com a Ciência e a Tecnologia, Foundation for Science and Technology.

Dolbeth, J., \& Rocha, D. (2020). O brinquedo tradicional em Alfena: uma história ilustrada [The traditional toy in Alfena: an illustrated story]. In Tavares, P., and Teixeira, P.M. (eds.), Proceedings of Confia 2020 - 8th International Conference on Illustration and Animation. Barcelos: Instituto Politécnico do Cávado e do Ave. 
Gomes, A. (2016). Design, tradition and craft: the case of Almalaguês. Oral presentation. Porto: PhD Design Forum, University of Porto.

Jokilehto, J. (1999). A history of architectural conservation. London: Butterworth-Heinemann.

Pink, S. (2007). Doing visual ethnography. London: Sage.

Polanyi, M.(1966). The tacit dimension. New York: Doubleday

Pye, D. (1968). The nature and art of workmanship. London : Cambridge University Press,

Rose, G. (2011). Visual Methodologies: an introduction to the interpretation of visual materials (3rd ed.). London: Sage.

Schwarz, M. and Yair, K. (2010). Making value: craft \& the economic and social contribution of makers. London: Crafts Council.

Sennett, R. (2008). The craftsman. New Haven: Yale University Press.

Thomas, N.J, Hackney, F. and Bunnell, K. (2011). Connecting craft and communities. In Connected Communities. London: Arts and Humanities Research Council.

Westecott, E. (2012). Independent game development as craft. Loading... The Journal of the Canadian Game Studies Association, 7 (11), 78-91.

Woolley, M. (2010). The making: Value and values in craft objects. In Valentine, L., and Follett, G. (Eds.), Past, present \& future craft practice (pp. 136-150). Edinburgh: NMS Enterprise.

Author Bios:

Heitor Alvelos

PhD Design (RCA, 2003); MFA (SAIC, 1992). Associate Professor at the University of Porto, where he directs the PhD Design and the Unexpected Media Lab / ID+ Research Center.

Current Chairman of the Scientific Board (HSS), Foundation for Science and Technology.

\section{Abhishek Chatterjee}

Design course leader at London School of Design and Marketing and integrated researcher at ID+, Research Institute for Design, Media and Culture / Unexpected Media Lab.

Research interests include observing pedagogic complementarities between design, traditional crafts and media expressions.

Acknowledgements:

The authors wish to thank the Foundation for Science and Technology for the successful funding bids of ID+ and Anti-Amnesia. Further thanks to all Anti-Amnesia researchers, crafts associations and individuals involved, and all students and teachers involved in the aforementioned pedagogical activities. 